blow was received on the abdomen while the man was on duty. The widow and children of a constable fatally injured whilst on duty are entitled to compensation and pension. The question as to whether this blow "caused" the cancer was debated, but as over three years had elapsed it was felt that even if a blow might be a "cause " of cancer occasionally, the two could not be connected in this case.

Eastbourne.

\section{A CASE OF SYMMETRICAL GANGRENE OF THE LOWER LIMBS.}

BY R. W. WINSTANLEY, M.R.C.S. ENG., L.R.C.P. EDIN., \&C.

DURING an influenza epidemic such as we had in the early months of last year a general practitioner has little time to spare for elaborate note-taking, but the following case is so interesting in some of its features that $I$ have thought it worthy of record.

A married woman aged fifty-seven years consulted me on Jan. 25th, 1895, for pain in the abdomen. On Aug. 25th, 1885, I delivered her of a stillborn child by turning. She made a good recovery and from that time till she consulted me she had enjoyed fairly good health except that she suffered occasionally from rheumatic pains in the legs. She has had three living children and three stillborn and ceased to menstruate at fifty-four years. The abdominal pain was situated a little to the left of the umbilicus, was continuous, of a dull, aching character, and directed downward to the groin and through to the back. The bowels being confined were opened by a simple enema. This gave slight, but only temporary, relief. A blood-coloured discharge from the genitals, like an ordinary menstrual period, pointed to uterine or ovarian congestion, and bromide of potassium and other sedatives were given, but without effect on the pain, although the discharge soon ceased. There was some deep tenderness on palpation, but nothing definite in the way of a swelling could be detected. Morphia gave temporary ease, but more lasting relief was obtained by keeping the bowels open by aperients such as cascara sagrada. Eventually, after some six weeks, the pain gradually abated and for a while the patient seemed to be quite well again. On March 21st, after nursing her daughter through an attack of influenza, she herself was seized with that complaint and had a typical attack lasting four or five days, with slight congestion at the base of one lung. About the end of the week the temperature was normal and she seemed on the road to recovery when she complained of a smarting pain in the cenitals, which on examination was found to be caused by herpes of the labia majora. This yielded to quinine and local soothing applications, but left her very weak, and on this date she was seized with great pain extending down both legs to the feet, which were found to be cold, blue, and mottled, but not swollen. The pulse was 120 , irregular and intermittent, and the temperature was normal. The next day the cyanosis was seen to be extending equally to the middle third of both legs, the toes being much darker, so that the case looked very like Raynand's disease. The urine contained a considerable amount of albumin, and not having time to make a more elaborate examination myself I sent a specimen to the Clinical Research Assosiation, and their report was as follows:"Reaction strongly acid; specific gravity, 1020; colour, dark straw; albumin, considerable quantity; blood, nil; nor were the bands seen through the spectroscope; sugar, nil urea, 2.76 per cent. A large deposit of urates was present; squamous epithelial cells were also abundant. There was no traces of either normal or broken-down blood corpuscles nor were there any casts or crystals. The urobilin band was seen very distinctly." The legs were extremely painful when touched, and, though quite cold, felt burning hot to the patient. The cyanosis increased and the toes became black and shrivelled. On April 7th the patient on being moved to another room-owing to the bursting of a waterbed on which she was lying-complained of pain in the abdomen, which was found to be decidedly swollen and tympanitic. This subsided again in a day or two, but bedsores now formed very rapidly on both buttocks, aphthæ appeared on the tongue and lips, and the patient got very low. The morphia given for the relief of pain was gradually increased; stimulants and nourishment being freely given the patient's strength somewhat revived. On the 12th the pain was rather less and from this time continued so with occasional exacerbations. The gangrene spreading up the legs reached the knees and large bullæe formed on the calves. The cyanosis at length extended to the inner side of the thighs and large sloughs formed on both buttocks. The patient gradually sank and died on May 8th.

Necropsy.-On post-mortem examination the body was found to be generally emaciated. In the thorax the lungs, heart, and large vessels were found to be quite healthy and normal In the abdomen all the viscera appeared normal except the kidneys, which were both studded with small cysts on the outer borders and anterior surfaces. On exposing the abdominal aorta it was seen to be distended with clot for about two inches above the bifurcation into the common iliac arteries. The said clot extended down the left iliac into the femoral. There was no clot in the right common iliac artery. On opening the aorta and turning aside the clot a small patch of calcareous degeneration was found at the commencement of the left common iliac artery and close to the fork. Otherwise these arteries appeared healthy. I was successful in removing and preserving the lower end of the abdominal aorta with the common iliac arteries containing the clot, and the specimen may now be seen in the museum of University College Hospital.

As to the treatment, several drugs were tried for the relief of the pain, and thyroid extract was given for a short time, but without any apparent benefit. Hypodermic injections of morphia and atropine and solid opium internally seemed to give most relief. The family history is remarkable. The father is stated to have died, aged seventy years, from mortification of the feet. The mother had one leg amputated for white swelling of the knee-joint, and is also stated to have died from mortification of the other foot aged fifty-seven years. One brother had the right foot amputated for disease of bones of the foot following a blow from a cricket ball (probably strumous). Another brother, still living, suffered from Bright's disease two years ago, is now quite weil, and is sixty-one years of age. There are two daughters living, aged thirty years and twenty-four years respectively. Both have enlarged veins in the lower limbs and both have suffered recently from phlebitis following influenza.

Haslemere, Surrey.

\section{A CASE OF SARCOMA OF THE ORBIT; RECURRENCE FIFTEEN MONTHS AFTER REMOVAL.}

BY F. H. KNAGGS, M.R.C.S. ENG., I.R.C.P. LOND.

C.ASES of sarcoma arising from the orbit itself are so infrequently met with in general practice that I venture to record the following.

On May 16th, 1894, a little girl aged two years and nine months was brought to me by Dr. Ernest Coward suffering from considerable protrusion of the left eyeball. The child had been very healthy, and nothing unusual in her appearance had been noticed till three weeks before, when her mother remarked that one eye appeared more prominent than the other; her father, however, would not acknowledge this till a week later, when Dr. Coward was asked to see the child, and he confirmed this rapid development of the disease, having seen the child previously when recently attending at the house. From this time the proptosis of the eyeball rapidly increased, though apparently without causing any inconvenience or distress to the child, who ate well, slept well, and, excepting this condition, appeared in robust health. There was no record of tumour in either the father's or mother's family and no history of injury. The child was well-nourished, bright, and cheerful. The temperature was normal, and had been so for the last fortnight. There was an absence of headache or vomiting. The left eyeball was proptosed, the cornea being on a level with the bridge of the nose, the hollow of the orbit was obliterated, the eyeball displaced downwards, forwards, and inwards; its movements were good internally. slight upward and downward, 


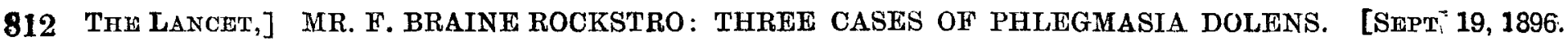

and none externally beyond the middle line. The lids did not cover the cornea when closed; there was no cedema or chemosis, the pupils were equal and reacted to light and accommodation, sight was good, she being able to distinguish between a pin and a needle with the affected eye. Ophthalmoscopic examination revealed only slight haziness of the lower margin of the optic disc, the remainder of the disc and retina being healthy. Palpation showed no increase in the tension of the eyebali but that the globe could not be pushed back into the orbit, it apparently impinging upon some firm unyielding substance behind. The brim of the orbit was free from any swelling, and between it and the globe no substance could be felt except in the situation of the lacrymal gland, which was pushed forward, but no undue hardness or enlargement was felt. The punctum and lacrymal ducts were normal. No pulsation was present, but a feeble systolic murmur was heard over both lids. The nose and throat were found to be free from disease and the hearing was good. in both ears. A week later (May 29th) the proptosis was much increased, the cornea becoming steamy; cedema of the conjunctiva commencing, and pain of a severe nature coming on, induced the parents to consent to an operation. Having removed the eyeball in the usual way under an anæsthetic I came down upon a considerable sized tumour enclosed in a thick capsule lying deep in the orbit. Incising the capsule enabled me to pass a strong pair of curved excision scissors easily round the growth, which was found attached to the apex of the orbit. Severing bhis, the tumour was easily lifted out; the attachment was seized and cut closely away from the apex. There was free hæmorrhage, which was easily controlled by pressure. Having thoroughly washed out the cavity with sublimate lotion it was then packed with iodoform gauze and a thick pad of Gamgee bound on. The case went on very well, the temperature never rising above $99^{\circ} \mathrm{F}$., and she was running about again in three weeks. I saw the patient in May, 1895, a year after the operation. There was then no sign of recurrence, and the littie girl was in the best of health and spirits. In July, 1895, fifteen months after the operation, a small hard nodule the size of a pea and attached to the upper and inner wall of the orbit was first detected. The parents refused further operative measures. The growth rapidly extended, in two months being outside the orbit, and before death, which occurred in February 1896, was a large conical mass protruding from the orbit, its apex being three inches in advance of the bridge of the nose. Right sided paralysis, convulsions, and coma preceded the end. The tumour removed was as large as a good sized walnut in its shell, entire on removal, and its attachment was simple connective tissue. A section of the tumour was made for me at Guy's Hospital, and the growth was found to be a large round-celled sarcoma. The eyeball was carefully examined and was found to be free from disease. I did not use the chloride of zinc paste after removal seeing that the tumour was so completely isolated.

Remarks.-The extreme rapidity of growth combined with the youth of my patient was strongly in favour of the tumour turning out to be malignant. That the growth was limited to the orbit seemed probable from the absence of disease in the nose, throat, antrum, mouth, and lacrymal ducts, and from the absence of œdema and chemosis of the conjunctiva in the earlier stages, suggesting that the growth had not come into the orbit by the cavernous sinus. It seems probable that the tumour arose from the connective tissue of the orbit. The periosteal origin so common in these cases is, I think, disproved by the non-recurrence so long after removal of the growth, when it is remembered that the site of removal was not treated by escharotics.

Huddersfield.

New Sewage Works at NewPort, Isle of WrgHT.-On Sept. 2nd the Mayor of Newport (Mr. F. T Mew) inaugurated the new sewage disposal works for the borough, which have been constructed at a total cost of $£ 10,000$. A new collecting sewer picks up the various old outfalls and conveys the sewage to the works, where it is treated with lime and ferric sulphate of alumina. The machinery includes sludge pumps and presses, mixing vats and wells, and steam power is employed. The three settling tanks are each calculated to hold 66,000 gallons. The sollecting sewer in one place goes under the river by means of an inverted syphon-two 16.in. iron pipes. Six stormwater overflows into the river are provided. Mr. Baldwin Latham was the engineer of the works.

\section{THREE CASES OF PHLEGMASIA DOLENS.}

\section{By FRANK BRAINE ROCKSTRO, M.R.C.S. ENG.,} L.R C.P. LOND.

Three cases of phlegmasia dolens occurring in the virgin having been reported in THE LANCEN at the end of last year, ${ }^{1}$ which have attracted considerable attention on account of the rarity of the condition under such circumstances, the following notes of three cases may also be of interest.

CASE 1.-A girl aged eighteen years had been suffering from ordinary chlorosis with its usual concomitants for some time, and had had amenorrhoea for three months. The present illness began on Nov. 5th, 1893, when the patient was at church; she felt faint and was obliged to be brought home, but by the following day she had recovered sufficiently to be able to work as usual. On the 7th, however, she was so giddy and faint that she was forced to abandon her duties and return to her home. She stayed in the house and did nothing for several days with no other indisposition beyond a feeling of malaise, and weakness of the lower extremities. On the 15th I first saw her. She complained of great weakness and pain in the sacral and lumbar regions and the left thigh in front at about the upper half, the latter place being some. what tender. She was unable to walk, and was obstinately constipated. On the 17th I found the left thigh somewhat swollen and whitish ; there was no pitting. The left leg and foot were also cedematous and pitted on pressure. I noticed, on the patient lying prone on her abdomen, that the left buttock was half as broad again as the right. There was tenderness along the back of the thigh, at the back of the knee-joint, and in Scarpa's triangle, also in the region of the colon throughout. The temperature was $103^{\circ} \mathrm{F}$. I could find nothing to account for her condition and nothing could be elicited as to her habits that was suspicious. She exhibited all the familiar signs of anæmia, with bruit-de-diable (bilateral) in the neck, anorexia, slight dyspncea as she lay in bed, and a mitral systolic bruit was audible over the sternum conducted over the chest to the axilla and back. During the following days the temperature gradually fell as the size of the left limb increased. On the 18th her morning temperature was $103^{\circ}$; on the 19 th, $102.8^{\circ}$; and on $20 \mathrm{th}, 102 \cdot 6^{\circ}$. The left lower extremity was quite white, pitting on pressure everywhere as high as the buttock behind and Poupart's ligament in front. There was intense tenderness in the left groin. The evening temperature on the same day was $102 \cdot 6^{\circ}$. On the morning of the 21 st it was $102 \cdot 2^{\circ}$. The lower limb was less swollen and less painful. No constitutional symptoms were complained of. On the $22 n d$ the morning temperature was $1016^{\circ}$, and the limb was still less swollen. The evening temperature was $101.8^{\circ}$. The morning temperature on the 23rd was $1014^{\circ}$. A well-marked tender cord (the external saphenous vein) was felt behind the left knee-joint; also an ill-defined tender mass in Scarpa's triangle. On the 24th the lower limb was less cedematous than the day preceding, and painfulness was not so much complained of. On the 25th the patient felt better than she had during the whole of the present illness and was cheerful, The bowels now acted ragularly. She was still ghastly anæmic. On the 26th, at 9 A.M., the patient overruled her nurse and sat out of bed on the night commode, when she suddenly felt very faint and distinctly felt something move from her thigh upwards into her body, how far she could not locate. Palpitation quickly set in, and urgent dyspncea. When I saw her some hours later she was suffering great distress at the epigastrium and in the cardiac area; there was dyspnoea; the respiration was about 60 , rather irregular, like panting; the pulse was very quick (144) and irregular in rhythm as well as in volume. A depression could distinctly be felt in the left Scarpa's triangle, where a clot had become dislodged. On the 27th when I saw her in the morning, the pain at the præcordium was gone. The patient now complained of pain in the right side like stitch and a slight cough with no spatum, giving pain during the act in an area in the right side between the sixth and seventh ribs about in a line with the anterior axillary fold. There was no dulness over this area, but the breath sounds were weak in a somewhat circular patch the size of a crown-piece, with slight sound of crepitation, 